\title{
KERAGAAN AGROINDUSTRI KELAPA PARUT KERING (DESICCATED COCONUT) (Studi Kasus Pada Agroindustri Kelapa Parut Kering di Desa Cidadali Kecamatan Cikalong Kabupaten Tasikmalaya)
}

\author{
DESICCATED COCONUT \\ (Case Study in Dry Grated Coconut Agroindustry in Cidadali Village, \\ Cikalong District, Tasikmalaya District)
}

\author{
ARIF BAHTIAR ${ }^{1 *}$, TRISNA INSAN NOOR $^{2}$, H. BUDI SETIA ${ }^{1}$ \\ ${ }^{1}$ Fakultas Pertanian Universitas Galuh \\ ${ }^{2}$ Fakultas Pertanian Universitas Padjajaran \\ Email : ambarokah2018@gmail.com
}

\begin{abstract}
ABSTRAK
Penelitian ini bertujuan untuk mengetahui : 1) Proses produksi agroindustri kelapa parut kering (desiccated coconut), 2) Besarnya Penerimaan dan pendapatan agroindustri kelapa parut kering (desiccated coconut) dalam satu kali proses produksi, 3) Besarnya price cost margin (PCM) agroindustri kelapa parut kering (desiccated coconut) dalam satu kali proses produksi. Penelitian ini dilaksanakan di Desa Cidadali Kecamatan Cikalong Kabupaten Tasikmalaya dengan menggunakan sampel penelitia adalah agroindustri kelapa parut kering (desiccated coconut) bapak Asep di Desa Cidadali Kecamatan Cikalong Kabupaten Tasikmalaya. Data yang diperoleh dianalisis secara mix method, yaitu deskriptif kualitatif dan kuantitatif. Hasil penelitian menunjukkan bahwa : 1) proses produksi kelapa parut kering (desiccated coconut) meliputi seleksi bahan baku, pengeluaran tempurung dan kulit ari, pencucian dan stabilisasi, penggilingan/ pemarutan, pengeringan, pendinginan dan pengemasan, 2) Besarnya penerimaan dan pendapatan yang diperoleh agroindustri kelapa parut kering (desiccated coconut) adalah sebesar Rp.28.600.000 untuk penerimaan dan Rp. 1.995.000 untuk pendapatan, 3) price cost margin (PCM) yang diperoleh agroindustri kelapa parut kering (desiccated coconut) adalah $0,7 \%$.
\end{abstract}

Kata kunci : Agroindustri, kelapa parut kering, Keragaan, Analisis Biaya, Price Cost Margin.

\begin{abstract}
This study aims to determine: 1) The production process of desiccated coconut (2) desiccated coconut, 2) The amount of revenue and income of desiccated coconut (desiccated coconut) in one production process, 3) The amount of the price cost margin (PCM) of coconut agro-industry desiccated coconut in one production process. This research was conducted in Cidadali Village, Cikalong Subdistrict, Tasikmalaya District by using a sample of research as the desiccated coconut agro-industry of Asep in Cidadali Village, Cikalong Subdistrict, Tasikmalaya District. The data obtained were analyzed by mix method, which is descriptive qualitative and quantitative. The results showed that: 1) the desiccated coconut production process includes the selection of raw materials, expenditure of shell and epidermis, washing and stabilization, grinding / drying, drying, cooling and packaging, 2) the amount of revenue and income obtained by agro-industry desiccated coconut is Rp.28,600,000 for receipts and Rp. 1,995,000 for revenue, 3) the price cost margin (PCM) obtained by desiccated coconut agroindustry is $0.7 \%$.
\end{abstract}

Keywords: Agro-industry, dry grated coconut, performance, Cost Analysis, Price Cost Margin.

\section{PENDAHULUAN}

Agroindustri merupakan kegiatan

pemanfaatan hasil pertanian menjadi produk olahan yang bernilai ekonomi, sekaligus menjadi suatu tahapan pembangunan pertanian berkelanjutan. Hal 
ini didukung dengan adanya keunggulan karakteristik yang dimiliki agroindustri, yaitu penggunaan bahan baku dari sumberdaya alam yang tersedia di dalam negeri (Soekartawi, 2010).

Kelapa merupakan salah satu komoditi perkebunan yang memiliki nilai ekonomis tinggi. Bagian tanaman kelapa yang memiliki nilai ekonomi yang tinggi adalah biji buah dan kulitnya yang digunakan sebagai bahan industri minuman, makanan, farmasi dan kosmetik. Disamping itu salah satunya buah kelapa dapat digunakan sebagai desiccated coconut (kelapa parut kering).

Di beberapa Kecamatan yang ada di Kabupaten Tasikmalaya, khususnya Kecamatan Cikalong tanaman kelapa mempunyai peranan ekonomi dan sosial, karena komoditi kelapa merupakan komoditas yang sudah bisa dirasakan manfaatnya oleh para petani yang membudidayakannya. Kelapa mulai berproduksi normal pada umur 7 tahun, walaupun ada yang sudah berbuah pada umur 5 tahun. Kemudian mampu berproduksi sampai berumur 70 tahun. Dalam aspek budidaya tanaman kelapa termasuk tanaman-tanaman yang tidak memerlukan pemeliharaan khusus, dengan pemeliharaan yang sederhana saja masih mampu berbuah. Dari sisi buah, kelapa dapat berbuah sepanjang tahun dan dipanen dua kali sepanjang tahun sehingga bisa menjadi pilihan komoditi yang dapat memberikan sumbangan pendapatan bagi para petani yang membudidayakannya.

\section{Perkembangan harga desiccated} coconut (kelapa parut kering) di pasaran Internasional jauh lebih tinggi dibanding produk-produk olahan kelapa lainnya. Sehingga harga desiccated coconut hampir dua kali lipat dari minyak kelapa. Disamping itu, rendeman pada pengolahan kelapa parut kering juga lebih tinggi. Karena $1 \mathrm{~kg}$ kelapa parut kering dihasilkan dari 8-9 butir kelapa, sedangkan $1 \mathrm{~kg}$ minyak kelapa diperoleh dari 10-12 butir kelapa. Faktor lain yang lebih menguntungkan adalah peluang pasar yang tersedia dan juga proses pengolahannya cukup sederhana (Palungkun, 1992).

\section{METODE PENELITIAN}

Metode penelitian yang digunakan dalam penelitian ini adalah mix methods. Mix Methods yaitu suatu langkah penelitian dengan menggabungkan dua bentuk pendekatan dalam penelitian, yaitu kualitatif dan kuantitatif. Penelitian campuran (mix methods) merupakan pendekatan penelitian yang mengkombinasikan antara penelitian kualitatif dengan penelitian kuantitatif (Creswell, 2010). 
Jenis penelitian yang akan digunakan dalam penelitian ini adalah metode studi kasus. Metode studi kasus merupakan salah satu metode penelitian yang dilakukan secara intensif, terperinci dan mendalam terhadap suatu organisme (individu), lembaga atau gejala tertentu dengan daerah atau subjek yang sempit selama kurun waktu tertentu (Arikunto, 2004). Metode studi kasus digunakan untuk memperoleh data secara lengkap dan rinci pada agroindustri kelapa parut kering (desiccated coconut) tersebut mengenai keragaan agroindustri yang dimulai dari kegiatan proses produksi hingga kegiatan pemasaran.

\section{Sumber dan Teknik Pengumpulan Data}

Sumber data yang digunakan dalam penelitian ini adalah data primer dan data sekunder. data primer adalah sumber data yang langsung memberikan data kepada pengumpul data. Data primer diperoleh secara langsung dari pemilik agroindustri kelapa parut kering (desiccated coconut) dengan metode wawancara berdasarkan daftar pertanyaan yang telah disiapkan (kuesioner). data sekunder adalah sumber data yang tidak langsung memberikan data kepada pengumpul data, misalnya lewat orang lain atau lewat dokumen. Data primer diperoleh melalui studi literatur serta studi dokumentasi dari instansi terkait (BPS dan BP3K), perpustakaan, internet serta beberapa model penelitian terdahulu yang berkaitan dengan penelitian ini.

\section{Teknik Pengumpulan Data}

Teknik pengumpulan data dibutuhkan untuk mengumpulkan informasi (data) yang berhubungan dengan permasalahan terhadap penelitian. Teknik pengumpulan data yang digunakan yaitu teknik wawancara, observasi, studi literatur dan alat bantu.

\section{HASIL DAN PEMBAHASAN}

\section{Identitas Responden}

Data yang digunakan untuk memberi gambaran umum mengenai identitas responden meliputi umur, pendidikan, pengalaman berusaha dan jumlah tanggungan keluarga.

Umur merupakan salah satu faktor yang dapat mempengaruhi seseorang dalam bekerja, semakin tua umur seseorang maka kemampuan fisik dalam bekerja semakin berkurang. Bapak Asep yang dijadikan sebagai responden berumur 37 tahun sehingga termasuk dalam usia produktif.

Tingkat pendidikan sangat penting peranannya terhadap seseorang dalam kegiatan suatu usaha, karena tingkat pendidikan dapat mempengaruhi seseorang dalam menerima dan melaksanakan hal-hal 
yang baru. Pendidikan responden sendiri adalah tamatan Perguruan Tinggi (D3).

Tanggungan keluarga merupakan salah satu faktor yang juga sangat erat kaitannya dengan kemampuan responden dalam mengelola usahanya. Semakin banyak jumlah tanggungan keluarga yang harus dipikul oleh seorang responden maka akan semakin termotivasi dalam melaksanakan dan menjalankan usahanya, dengan harapan pendapatan yang diperolehnya dapat mencukupi kebutuhan hidup keluarganya.

Pengalaman berusaha merupakan salah satu faktor juga yang menentukan keberhasilan dalam usaha agroindustri tahu. Semakin lama pengalaman berusaha maka akan semakin tinggi keterampilan dan ilmu yang dimiliki dalam melakukan proses produksi, yaitu dengan mempelajari pengalaman yang dialami sehingga akan lebih mampu dalam menghadapi kesulitan dan cara penanggulangannya. Pengalaman Bapak Ateng dalam berusaha agroindustri tahu yang dijadikan sebagai responden sudah cukup lama, yaitu sekitar 15 tahun.

Proses Produksi Kelapa Parut Kering ( Desiccated Coconut )

Proses pengolahan produk desiccated coconut prinsipnya mengeringkan daging buah kelapa pada kondisi yang sangat higienis (Rindengan,
1996). Tahap-tahap pengolahan diuraikan sebagai berikut :

1. Seleksi bahan baku

Seleksi bahan baku sangat penting untuk dilakukan, karena akan berhubungan dengan kualitas bahan baku yang digunakan sehingga menentukan mutu produk akhir yang akan dihasilkan.

2. Pengeluaran tempurung dan kulit ari Pengeluaran tempurung dan kulit ari dapat dilakukan secara manual ataupun mekanis yang dijalankan oleh para pekerja.

3. Pencucian dan Stabilisasi

Pencucian dan stabilisasi bertujuan untuk mencegah proses pencoklatan, memperbaiki warna produk, cita rasa dan mencegah pertumbuhan mikroba.

4. Pemarutan dan Pengeringan

Pemarutan daging buah kelapa dilakukan sesuai ukuran partikel yang diinginkan. Selanjutnya daging kelapa yang telah digiling kemudian dikeringkan. Pengeringan dilakukan menggunakan oven. 5. Pendinginan dan Pengemasan

Pendinginan produk dilakukan agar desiccated coconut yang akan dikemas tidak mengandung uap air. Pengemasan dilakukan agar produk yang dihasilkan higienis sehingga akan memiliki masa simpan yang cukup lama.

\section{Analisis Usaha Agroindustri Kelapa}

Parut Kering (Desiccated Coconut) 


\section{Analisis Biaya}

Biaya Tetap

Biaya tetap (fixed cost) adalah biaya yang besar kecilnya tidak dipengaruhi oleh besar kecilnya produksi dan sifatnya tidak habis dalam satu kali proses produksi, yang terdiri atas pajak bumi dan bangunan, penyusutan alat, dan listrik. Biaya tetap yang dikeluarkan oleh agroindustri kelapa parut kering ( desiccated coconut) di Desa Cidadali dapat dilihat pada Tabel 1.

\section{Tabel 1. Biaya Tetap Total}

\begin{tabular}{|c|c|c|}
\hline No & Biaya Tetap & Jumlah(Rp) \\
\hline 1. & $\begin{array}{l}\text { Pajak Bumi dan } \\
\text { Bangunan }\end{array}$ & 20,000 \\
\hline 2. & Penyusutan Alat & $10,565,000$ \\
\hline 3. & Listrik & 200,000 \\
\hline & Total & $10.785,000$ \\
\hline
\end{tabular}

Tabel 1 menunjukkan besarnya biaya tetap total yang dikeluarkan dalam satu kali proses produksi adalah Rp 10.785,000.

\section{Biaya Variabel}

Biaya Variabel (variable cost) adalah biaya yang besar kecilnya dipengaruhi oleh besar kecilnya produksi, dan sifatnya habis dalam satu kali proses produksi yang terdiri atas biaya penyediaan bahan baku, transportasi (sarana produksi) dan tenaga kerja. Biaya variabel yang dikeluarkan oleh agroindustri kelapa parut kering (desiccated coconut) di Desa Cidadali dapat dilihat pada Tabel 2.

\section{Tabel 2. Biaya Variabel Total}

\begin{tabular}{ccr}
\hline No & Biaya Variabel & \multicolumn{1}{c}{ Jumlah $(\mathbf{R p})$} \\
\hline 1. & Sarana Produksi & 8.300 .000 \\
2. & Tenaga Kerja & 7.560 .000 \\
\hline & Total & $\mathbf{1 5 . 8 6 0 . 0 0 0}$ \\
\hline
\end{tabular}

Tabel 2 menunjukkan besarnya biaya variabel total yang dikeluarkan oleh agroindustri kelapa parut kering (desiccated coconut) di Desa Cidadali dalam satu kali proses produksi adalah Rp 15.860.000.

\section{Biaya Total}

$$
\text { Biaya total merupakan }
$$
penjumlahan biaya tetap total dengan biaya variabel total. Biaya total pada agroindustri kelapa parut kering (desiccated coconut) di Desa Cidadali dalam satu kali proses produksi dapat dilihat pada Tabel 3.

\section{Tabel 3. Biaya Total}

\begin{tabular}{ccr}
\hline No & Biaya Total & Jumlah (Rp) \\
\hline 1. & Total Biaya Tetap & $10.785,000$ \\
2. & Total Biaya Variabel & 15.860 .000 \\
\hline & Total & $\mathbf{2 6 . 6 4 5 . 0 0 0}$ \\
\hline
\end{tabular}

Tabel 3 menunjukkan bahwa biaya total yang dikeluarkan oleh agroindustri kelapa parut kering (desiccated coconut) di Desa Cidadali dalam satu kali proses produksi sebesar Rp 26.645.000. 


\section{Analisis Penerimaan}

Penerimaan agroindustri kelapa parut kering (desiccated coconut) di Desa Cidadali ini dihitung dengan cara mengalikan hasil produksi kelapa parut kering (desiccated coconut) dalam satu kali proses produksi dengan harga jual saat penelitian selama satu kali proses produksi. Penerimaan hasil agroindustri kelapa parut kering (desiccated coconut) di Desa Cidadali untuk satu kali proses produksi dapat dilihat pada Tabel 4.

Tabel 4. Penerimaan Total

\begin{tabular}{ccccr}
\hline No & Produk & $\begin{array}{c}\text { Jumlah } \\
\text { Produksi }\end{array}$ & Harga & \multicolumn{1}{c}{ Jumlah (Rp) } \\
\hline 1. & Desiccated Coconut & $2.200 \mathrm{~kg}$ & $\mathrm{Rp} 13.000 / \mathrm{kg}$ & 28.600 .000 \\
\hline \multicolumn{7}{r}{ Jumlah } & & $\mathbf{2 8 . 6 0 0 . 0 0 0}$ \\
\hline
\end{tabular}

Tabel 4 menunjukkan bahwa penerimaan total pada agroindustri kelapa parut kering (desiccated coconut) di Desa Cidadali dalam satu kali proses produksi sebesar Rp 28.600.000 yang berasal dari penjualan kelapa parut kering (desiccated coconut).

\begin{abstract}
Analisis Pendapatan
Pendapatan adalah selisih antara penerimaan total dengan biaya total. Penerimaan agroindustri kelapa parut kering (desiccated coconut) di Desa Cidadali dapat dilihat pada Tabel 5.
\end{abstract}

\section{Tabel 5. Pendapatan Total}

\begin{tabular}{llc}
\hline No & \multicolumn{1}{c}{ Uraian } & Jumlah $(\mathbf{R p})$ \\
\hline 1. & Total Penerimaan & 28.600 .000 \\
\hline 2. & Biaya Total & 26.645 .000 \\
\hline & $\quad$ Total Pendapatan & $\mathbf{1 . 9 5 5 . 0 0 0}$ \\
\hline
\end{tabular}

Tabel 5 menunjukkan pendapatan yang diperoleh agroindustri kelapa parut kering (desiccated coconut) di Desa Cidadali dalam satu kali proses produksi sebesar Rp 1.955.000. Pendapatan ini merupakan selisih dari penerimaan $\mathrm{Rp}$ 28.600.000 dengan biaya total $\mathrm{Rp}$ 26.645.000.

\section{Analisis PCM ( Price Cost Margin )}

PCM adalah rasio keuntungan terhadap total biaya, dan dihitung dengan rumus sebagai berikut:

$$
\begin{aligned}
\mathrm{PCM} & =\frac{\mathrm{TR}-\mathrm{TC}}{\mathrm{TR}} \\
& =\frac{28.600 .000-26.645 .000}{28.600 .000} \\
& =0,7
\end{aligned}
$$


Berdasarkan hasil perhitungan bahwa rasio keuntungan terhadap total biaya pada agroindustri kelapa parut kering (desiccated coconut) di Desa Cidadali dalam satu kali proses produksi sebesar 0,7 $\%$. Artinya perusahaan kecil potensinya untuk dapat menaikan harga produk.

\section{Nilai Tambah Produk Kelapa ParutKering ( Desiccated Coconut )}

Nilai Tambah pada Agroindustri Kelapa Parut Kering( Desiccated Coconut ) sudah positif, selain dari produk kelapa parut kering ( desiccated coconut ), kemudian mendapa tnilai tambah dari hasil limbah hasil produksi seperti tempurung kelapa dan air kelapa.

Bauran Pemasaran Produk Kelapa Parut Kering ( Desiccated Coconut )

Bauran pemasaran (Marketing mix) adalah seperangkat alat pemasaran yang digunakan perusahaan untuk mencapai tujuan pemasaran dalam memenuhi target pasarnya. Ada empat variable yaitu :produk, harga, tempat dan promosi atau dikenal dengan istilah "4P" yaitu, product, price, place, dan promotion.
Bauran

pemsaran

pada Agroindustri Kelapa Parut Kering (Desiccated Coconut) di Desa Cidadali Kecamatan Cikalong Kabupaten Tasikmalaya hanya dari aspek produk saja, karena untuk harga, tempat dan promosi sudah ditentukan oleh perseroan terbatas (PT), dengan spesifikasi produk yang sudah ditentukan, antara lain berwarna putih dan berukuran medium, apabila terjadi ketidak sesuaian , maka produk di reject atau masuk kelas 2 dengan dibayar setengah harga dari harga yang ditentukan.

\section{Saluran Pemasaran Produk Kelapa ParutKering (Desiccated Coconut)}

Saluran pemasaran produk agroindustri Kelapa Parut Kering (Desiccated Coconut) di Desa Cidadali Kecamatan Cikalong Kabupaten Tasikmalaya yaitu 0 (nol) tingkat, yaitu dari Agroindustri Kelapa Parut Kering ke Perseroan Terbatas (PT). Untuk lebih jelasnya bias ditunjukkan pada gambar berikut :

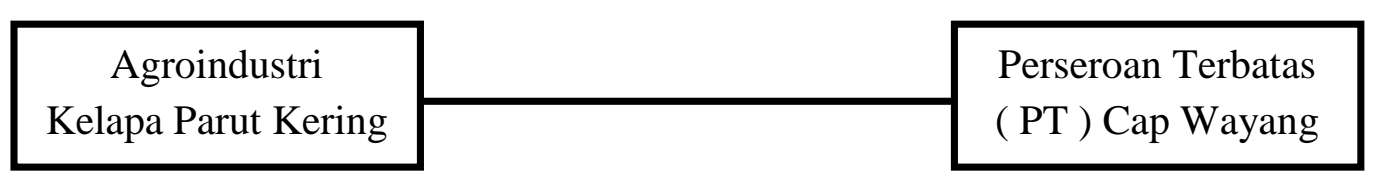

Gambar 1. Saluran Pemasaran agroindustri kelapa parut kering (desiccated coconut) 


\section{KESIMPULAN DAN SARAN}

\section{Kesimpulan}

Berdasarkan penelitian yang telah dilakukan, maka dapat disimpulkan sebagai berikut:

1. Keragaan produksi agroindustri kelapa parut kering (dessicated coconut) sudah baik karena sudah menggunakan mesin sehingga kualitas produk sesuai dengan kriteria perusahaan di pasaran.

2. Berdasarkan penelitian yang telah dilakukan maka penerimaan sebesar Rp. 28.600.000 dan pendapatan sebesar Rp. 1.955 .000 pada agroindustri kelapa parut di Desa Cidadali Kecamatan Cikalong Kabupaten Tasikmalaya dalam satu kali proses produksi.

3. Berdasarkan penelitian yang telah dilakukan bahwa rasio keuntungan terhadap total biaya pada agroindustri kelapa parut kering (desiccated coconut) di Desa Cidadali dalam satu kali proses produksi sebesar $0,7 \%$. Artinya perusahaan tidak dapat menaikan harga produk.

\section{Saran}

Saran yang dapat diberikan berdasarkan hasil penelitian ini adalah:
1. Bagi pengusaha agroindustri kelapa parut kering (dessicated coconut) agar dapat mengembangkan usahanya, menciptakan produk baru sehingga mendapatkan peluang baru dalam usahanya.

2. Bagi dinas terkait yaitu Dinas Koperasi, Perindustrian dan Perdagangan Kabupaten Tasikmalaya hendaknya dapat lebih mendukung pengembangan usaha, salah satunya dengan memberikan pembinaan terhadap anak muda, sehingga tercipta para pelaku usaha muda, mandiri dan kreatif khususnya di bidang produk pertanian.

3. Bagi peneliti lain sebaiknya melakukan penelitian lanjutan terhadap pemasaran agroindustri kelapa parut kering (dessicated coconut) dalam penelitian ini agar tidak hanya dari agroindustri langsung ke PT.

\section{DAFTAR PUSTAKA}

Hastinawati, I. dan M. Rum. 2012. Keragaan Agroindustri Kerupuk Udang Di Kecamatan Kwanyar Kabupaten Bangkalan. Agriekonomika, 1(1) : 15-24. http://id.portalgaruda.org/index.ph p?page $=18 \&$ ipp $=10 \&$ ref $=$ browse $\&$ mod=viewjournal\&journal=6194. 
Herdiansyah, H. 2010. Metode Penelitian Kualitatif untuk Ilmu-ilmu Sosial. Salemba Humanika. Jakarta.

Karouw, S., Barlina, R., dan Pasang, Patrik M.Pengolahan Dan Penyimpanan Desiccated Coconut (Kelapa Parut Kering. Journal.

Kementerian Pertanian, 2013. Pedoman
Kewirausahaan Agribisnis Jakarta.

M. Husain Makhluf. 2017.Analisis Hubungan Price Cost Margin Dan Market Share Dalam Kerangka Structure Conduct Performance (Scp). Journal. 